Polymer Journal, Vol. 39, No. 12, pp. 1345-1350 (2007)

(C) 2007 The Society of Polymer Science, Japan

\title{
Studies of Green Emission in Polyfluorenes Using a Model Polymer
}

\author{
Benqiao HE, ${ }^{1,2}$ Jing LI, ${ }^{2}$ Zhishan Bo, ${ }^{2}$ and Yong HuANG ${ }^{2, \dagger}$ \\ ${ }^{1}$ Tianjin Key Laboratory of Fiber Modification and Functional Fiber, School of Materials and Chemical Engineering, \\ Tianjin Polytechnic University, Tianjin 300160, China \\ ${ }^{2}$ State Key Laboratory of Polymer Physics \& Chemistry and Joint Laboratory of Polymer Science and Material, \\ Beijing National Laboratory of Molecular Science, Institute of Chemistry, CAS, Beijing 100080, China
}

(Received May 14, 2007; Accepted September 5, 2007; Published October 23, 2007)

\begin{abstract}
The green emission (g-band) in polyfluorene-based conjugated materials is studied by various spectroscopic methods on defined poly $\left(9,9^{\prime}\right.$-dioctylfluorene) with one foluorenone unit $\left(\mathrm{P}_{20}\right)$, which can be seen as a model compound for polyfluorene emitting g-band. The absorption and emission properties of $\mathrm{P}_{20}$ in the film and solution (room temperature) reveal the optical properties of the green emission emerging in polyfluorene-type polymer. All the experimental evidence obtained demonstrates that $\mathrm{g}$-band in polyfluorene is attributed to the mono-chain fluorenone; and the aggregation of the chains further suppresses the blue emission and enhances g-band.

[doi:10.1295/polymj.PJ2007041]

KEY WORDS Polyfluorene / Conjugated Polymer / Membrane / Green Emission /
\end{abstract}

Conjugated polymers serving as emitters in lightemitting diodes (LEDs) are attractive to the display industry because of their potential ability for easy and cost-effective processing by solution casting, excellent mechanical properties and structure controllability to tune electro- and photophysical properties. ${ }^{1-6}$ Among the conjugated polymers considered for LED application, polyfluorenes (PFs) have been viewed as the most promising blue-light materials due to their extremely high solution and solid-state quantum efficiency, good charge transport, excellent chemical and thermal stabilities and tunability of physical parameters through chemical modification and copolymerization. However, a long-wave emission in the region of 490-550 nm, ${ }^{7-10}$ i.e. green emission ("g-band" for short), appears in the PFs spectra after ultraviolet light exposure, heating in the air or passage of current. The appearance of g-band is undesirable for two reasons: One is the reduction of the overall quantum efficiency, and the other is the impurity of the blue emission. Therefore, many research groups are studying the origin of g-band in order to suppress g-band. G-band had been early believed to originate from the aggregate of polyfluorene or polyfluorene-based excimer. ${ }^{11-13}$ But the PFs studied in the literatures are often synthesized via the Yamamoto route whose conditions are harsher than Suzuki coupling method and often result in production of fluorenone during and after the polymerization. ${ }^{14-16}$ Therefore, the origin of aggregate of polyfluorene cannot be accepted. Afterward, Sims et al. proposed a origin of fluorenonebased excimer. ${ }^{17}$ In their experiment, g-band was not observed in PF/polystyrene blend film after UVexposure, which was believed to be due to polystyrene blocking the formation of fluorenone-based excimer. But the inter-chain distance in PF film (about 1.28 $\mathrm{nm}^{17}$ ) is beyond the distance for excimer formation (about $0.3 \mathrm{~nm}$ or less ${ }^{18}$ ). It is difficult to form the fluorenone-based excimer in such a situation. And the theoretical calculation is also against the origin of the fluorenone-based excimer. ${ }^{19}$ List et al. presented a new origin of fluorenone defect. ${ }^{15}$ and other experimental evidence supported the opinion. ${ }^{20,21}$ But some experimental phenomena cannot be well explained by the opinion of fluorenone-defect yet. ${ }^{4,22-27}$

Though the true origin of g-band (from fluorenone defect or fluorenone-based excimer) in the PF is not still clear, it is documented that the origin of $\mathrm{g}$ band is related to the occurrence of the fluorenone. ${ }^{8,15,17,28-30}$ Therefore, a model molecule that is a copolymer of fluorene and fluorenone had been used to clarify the green emission in polyfluorene and the mechanism of fluorenone defect was proposed. ${ }^{8}$ But the occurrence of fluorenone segment (without alkyl substituent groups) in copolymer may allow the approach of aromatic groups to distance of $0.3 \mathrm{~nm}$ for excimer formation. Therefore, the validity of the model molecule was doubted.

In this work, a new model molecule that contains only one fluorenone unit in the midst of the PF chain (denoted as " $\mathrm{P}_{20}$ ") was designed to clarify the exact nature of g-band emission in the PF. The spectral properties of the model molecule in solution and film are investigated in detail. All the experimental evi-

${ }^{\dagger}$ To whom correspondence should be addressed (Tel: +86-10-68597350, Fax: +86-10-68597356, E-mail: yhuang@ cashq.ac.cn). 


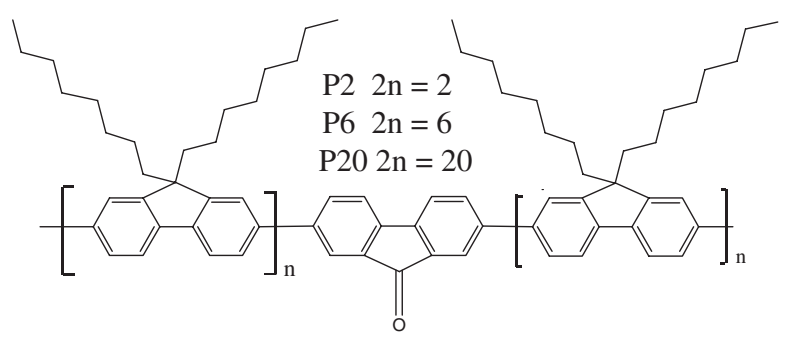

Figure 1. The structure formula of $\mathrm{P} 2 \mathrm{n}$.

dence obtained demonstrates g-band in polyfluorene is attributed to the mono-chain fluorenone; more important, the aggregation of the chains suppresses the blue emission and enhances g-band.

\section{EXPERIMENTAL}

\section{Materials}

The model polymer (denoted as " $\mathrm{P}_{20}$ ") was polyfluorene containing one fluorenone unit in the chain, which was synthesized and characterized in our laboratory. The detailedly synthetical procedure was introduced in our previous literature. ${ }^{31}$ The ratio of fluorenone unit to fluorene unit in $\mathrm{P}_{20}$ was around 1:20 according to the fed ratio and there is only one fluorenone unit in each $\mathrm{P}_{20}$ chain. Other two oligofluorenes containing one fluorenone unit (denoted as " $\mathrm{P}_{2}$ " and " $\mathrm{P}_{6}$ ") were also synthesized and studied in order to compare with $\mathrm{P}_{20}$. The $\mathrm{P}_{20}, \mathrm{P}_{6}$ and $\mathrm{P}_{2}$ (the figure is the number of repeat fluorene units) were called $\mathrm{P}_{2 n}$ by a joint name. The structure formula of $\mathrm{P}_{2 \mathrm{n}}$ is shown in Figure 1 . The poly $\left(9,9^{\prime}\right.$-dioctylfluorene) (PF) was synthesized according to Suzuki polycondensation method. ${ }^{32}$ The molecular weight $\left(M_{\mathrm{n}}=\right.$ $\left.9000, M_{\mathrm{w}} / M_{\mathrm{n}}=2.6\right)$ of PF was determined by gel permeation chromatography (GPC) calibrated with polystyrene standard.

\section{Solution Preparation}

All solutions were prepared by first dissolving the appropriated amount of polymer into a solvent and then heated in oil bath at $50^{\circ} \mathrm{C}$ with stirring for $24 \mathrm{~h}$ to fully dissolve.

\section{Spectral Characterization}

The UV-vis absorption spectra were recorded by a spectrophotometer of SHIMADZU, UV-1601PC. Steady state photo-luminescent (PL) spectra were recorded by a fluorescence photometer (VARIAN, Cary Eclipse, FLR025). The photo-luminescent lifetime measurements were performed with an Edinburgh Analytical Instruments (FLS-920). All spectral characterizations were carried out at room temperature.

\section{RESULTS AND DISCUSSION}

Spectral Characterization of P20 Film and PF Film After UV-light Exposure for $24 \mathrm{~h}$

There are two reasons to choose $\mathrm{P}_{20}$ molecule as the model molecule. Firstly, the structure of $\mathrm{P}_{20}$ is nearly identical to that of the PF except one fluorenone unit, which makes the $\mathrm{P}_{20}$ well miscible with the PF. Secondly, the interaction between fluorenone units will be restricted because the fluorenone unit is packed by fluorene units, which is different the random copolymers of fluorene and fluorenone reported in literatures. ${ }^{8}$

In order to ensure that $\mathrm{P}_{20}$ is a valid model polymer for the PF emitting green band, the spectral studies of the pure PF exposed to UV-light have been firstly carried out. It is found that a new emission peak at $530 \mathrm{~nm}$ appears when PF film is exposed to UV-light for $1 \mathrm{~h}$. There is no emission peak at $530 \mathrm{~nm}$ in PF film before exposing (in the insert of Figure 2a). And the strength of g-band increases with increasing UV-light exposure time, which is identical to the phenomena reported by List et al. ${ }^{15}$ Figure 2 shows the PL and absorption spectra of PF film after UV-light exposure for $24 \mathrm{~h}$ (denoted as "PF-UV-24h") and the blend film containing $75 \% \mathrm{P}_{20}$ and $25 \% \mathrm{PF}$ (denoted as " $\mathrm{P}_{20} \mathrm{PF} 25$ "). The PL spectra of the two films have weak peaks at $424 \mathrm{~nm}$ and strong peaks at $532 \mathrm{~nm}$.
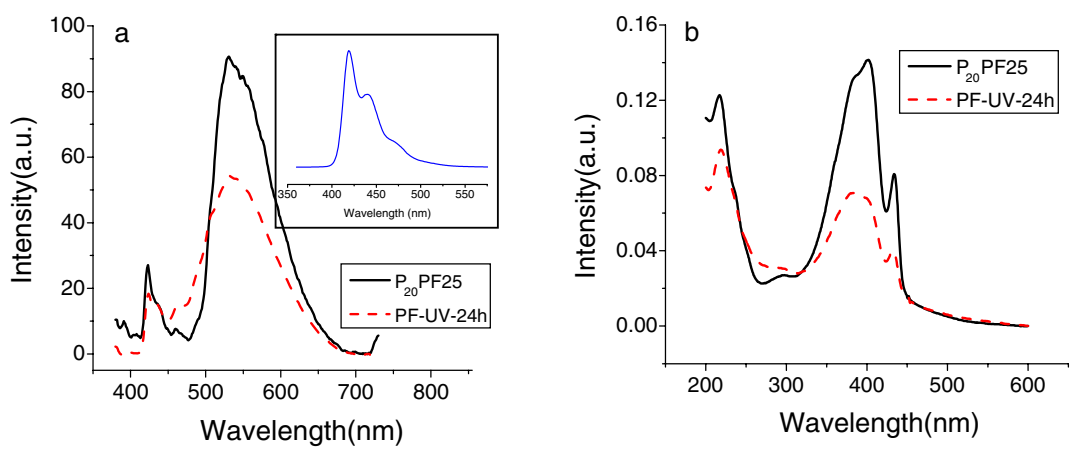

Figure 2. The emission (a) and absorbance (b) of PF-UV-24h (dash) and $\mathrm{P}_{20} \mathrm{PF} 25$ film (solid). The insert in (a) is the emission of pure PF before UV-exposure. 
The PL peaks at $424 \mathrm{~nm}$ come from PF or PF segment and the peaks at $532 \mathrm{~nm}$ are g-band mentioned above. The absorption spectra of the two films have $\pi-\pi^{*}$ transitions at $400 \mathrm{~nm}$ with shoulder peaks at $433 \mathrm{~nm}$. It is suggested that the PL and absorption spectra of the PF-UV-24h film are the same as those of the $\mathrm{P}_{20} \mathrm{PF} 25$ film.

Figure 3 shows the PL decays for g-band emissions of the PF-UV-24h film and the $\mathrm{P}_{20} \mathrm{PF} 25$ film. Their decay curves are measured by exciting at $450 \mathrm{~nm}$ with $200 \mathrm{ps}$ pulses and can be fit with single exponentials, ${ }^{17}$ yielding time constants of $6.656 \mathrm{~ns}$ for PF-UV-24h and $6.464 \mathrm{~ns}$ for $\mathrm{P}_{20} \mathrm{PF} 25$. From above experiment results, we believe that the $\mathrm{P}_{20}$ is a valid polymer for clarification of the exact nature of $\mathrm{g}$-band emission in the PF.

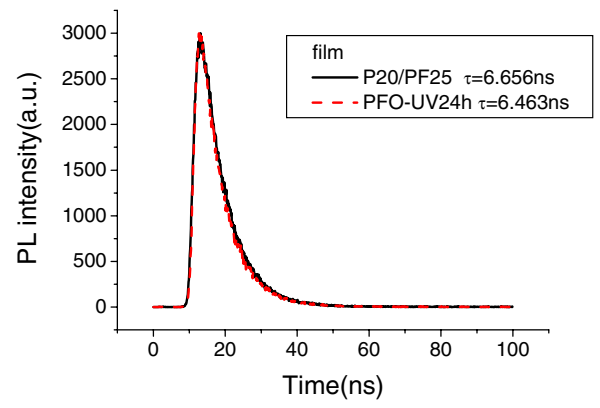

Figure 3. PL decays for g-band emission of PF-UV-24h film and $\mathrm{P}_{20} \mathrm{PF} 25$ film (excited at $450 \mathrm{~nm}$ ).

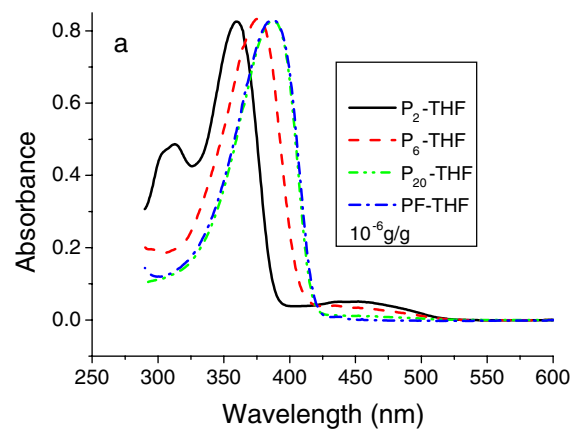

\section{Spectra of $P_{2 n}$ Solutions}

Figure 4 shows the absorption spectra of $\mathrm{P}_{2 \mathrm{n}}$ and $\mathrm{PF}$ in tetrahydrofuran (THF). The maximum absorptions at $360,376,387 \mathrm{~nm}$ are assigned to $\pi-\pi^{*}$ transition of main chain of $\mathrm{P}_{2}, \mathrm{P}_{6}, \mathrm{P}_{20}$, respectively, and a long-wave absorption peak at $453 \mathrm{~nm}$ is all clearly observed in $\mathrm{P}_{2}, \mathrm{P}_{6}, \mathrm{P}_{20}$ spectra and no absorption at $453 \mathrm{~nm}$ is observed in PF. The $\pi-\pi^{*}$ transitions are red shifted with increasing the conjugated length of $\mathrm{P}_{2 n}$ molecular chains (from $\mathrm{P}_{2}$, to $\mathrm{P}_{6}$, and to $\mathrm{P}_{20}$ ), which is the same as those of oligofluorene with comparative number of repeat unit. ${ }^{33}$ It is suggested that the fluorenone unit in $\mathrm{P}_{2 n}$ cannot destroy the conjugation along the PF backbone. The long-wave absorptions of $\mathrm{P}_{2 \mathrm{n}}$ assigned to $\mathrm{CT} \pi-\pi^{*}$ transition are unchanged with the conjugated length, which is consistent with the result of the quantum chemical calculation. ${ }^{19}$

The effect of the conjugated length of the $\mathrm{P}_{2 \mathrm{n}}$ chains on g-band emission is shown in Figure 5. Through exciting at $370 \mathrm{~nm}$ (in Figure 5a), the emission spectra only contain g-band and without blue emission for the $\mathrm{P}_{2}, \mathrm{P}_{6}$ samples. This is because that the excitation of the fluorene can entirely transfer to the fluorenone moieties. ${ }^{31}$ And for the $\mathrm{P}_{20}$ sample, the emission spectrum displays the regular PF feature except the longwave emission at $542 \mathrm{~nm}$. No emission at $542 \mathrm{~nm}$ is observed in PF. Exciting at $450 \mathrm{~nm}$, only g-band with maximum at $542 \mathrm{~nm}$ is observed. The position and the

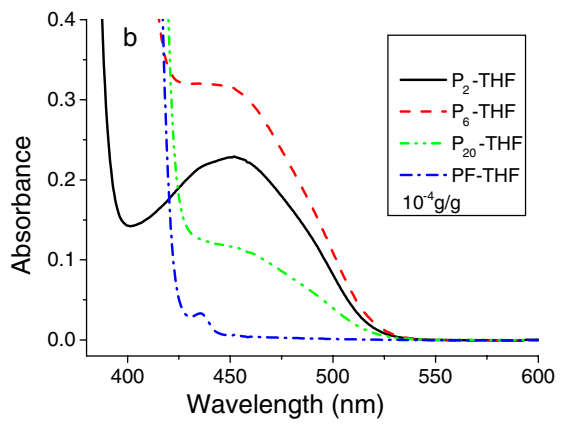

Figure 4. The absorption spectra of $\mathrm{P}_{2 \mathrm{n}}$ and PF in THF. a, $\pi-\pi^{*}$ transition; b, CT $\pi-\pi^{*}$ transition.
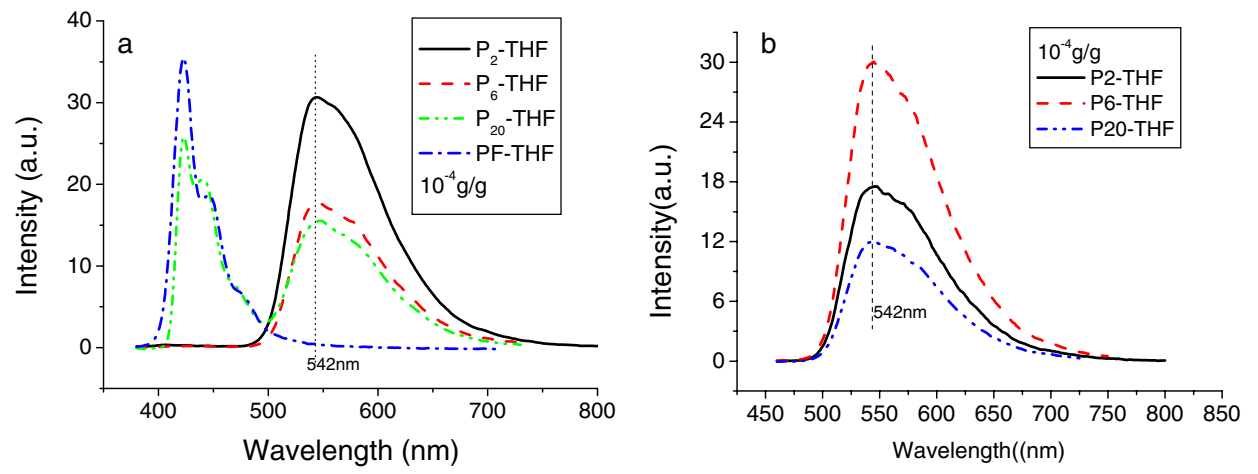

Figure 5. The PL spectra of $P_{2 n}$ and $P F$ in THF at the concentration of $10^{-4} \mathrm{~g} / \mathrm{g}$. a, excited at $370 \mathrm{~nm}$; b, excited at $450 \mathrm{~nm}$. 

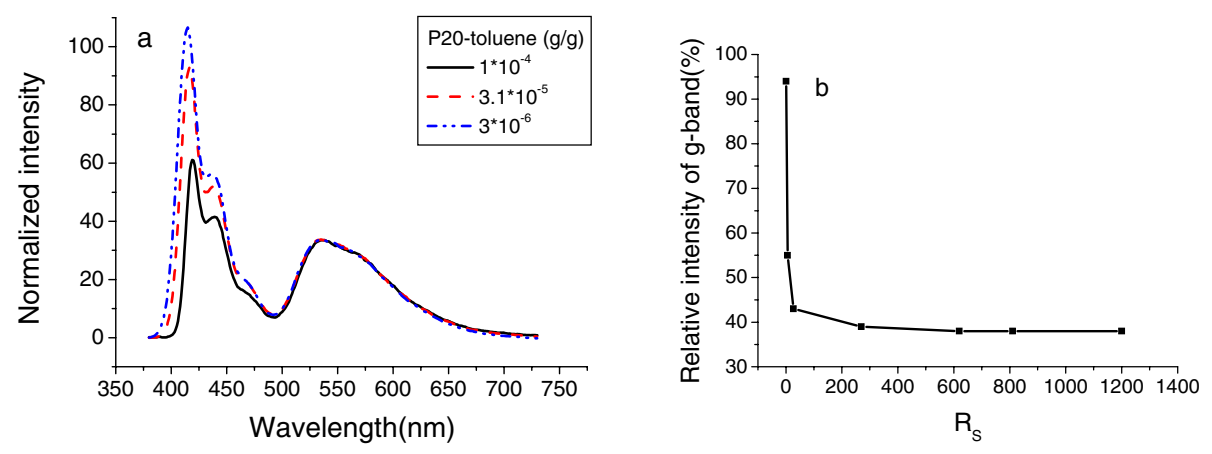

Figure 6. (a) The normalized PL spectra at different concentrations of $\mathrm{P}_{20} /$ toluene solution and (b) the relative strength of g-band at different multiple of dilution.
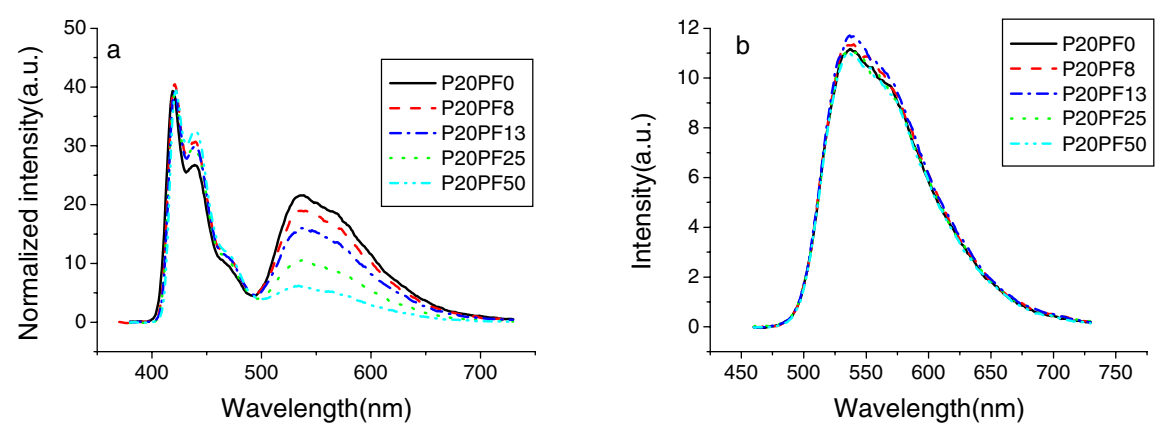

Figure 7. PL spectra of $\mathrm{P}_{20} / \mathrm{PF}$ in toluene. a, excited at $370 \mathrm{~nm}$, normalized spectra at $420 \mathrm{~nm}$; b, excited at $450 \mathrm{~nm}$. The concentration of $\mathrm{P}_{20}$ in solution is fixed at $10^{-4} \mathrm{~g} / \mathrm{g}$. the number ' $0,8,13,25,50$ ' in inset is the percentage of $\mathrm{PF}$ in $\mathrm{P}_{20} / \mathrm{PF}$ blend.

shape of g-bands are identical for the three samples (in Figure $5 b$ ). It is suggested g-band emission is localized in fixed conjugated length, which is consistent with the quantum-chemical calculation. ${ }^{19}$

The changes of the emission spectra and the relative strength of g-band with the change of the concentration of the $\mathrm{P}_{20}$ /toluene solution are shown in Figure 6 . The emission spectra are normalized at $530 \mathrm{~nm}$. The blue band and g-band are observed in the emission spectra. The blue band is blue shifted from $419 \mathrm{~nm}$ to $414 \mathrm{~nm}$ when the concentration changes from $1 \times$ $10^{-4}$ to $3 \times 10^{-6} \mathrm{~g} / \mathrm{g}$. This suggests the interaction of chains decreases and blue-emission efficiency will improve. But g-band is not shifted with changing the concentration and shows the identical shape and location, which suggests that the decrease of interaction of chains does not affect the emission properties of g-band. It can also be observed from the Figure 6b, that the relative strength of g-band is quickly decreased firstly and then keeps unchanged when the solution is diluted. The relative strength of g-band is $93 \%$ at the concentration of $10^{-3} \mathrm{~g} / \mathrm{g}$ PF in toluene. And when the solution concentration is decreased to lower than $5 \times 10^{-6}$, the relative strength is rapid decreased to $38 \%$, and then keeps unchanged when the concentration is further decreased. The rapid decrease of the relative strength of g-band is possibly due to the fast increase of the blue-emission efficiency of PF seg- ments with dilution of the solution. When the solution is very dilute, the PF segments blue-emission luminescent efficiency is unchanged any more with dilution of the solution. Therefore, the relative strength of g-band is unchanged during further diluting. The results are different from the phenomena common to excimer emission that can be vanished in very dilute solution, ${ }^{17,18}$ which further support the origin of monochain fluorenone of g-band emission.

\section{Spectra of $P F / P_{20}$ Blends}

The emission properties of the $\mathrm{PF} / \mathrm{P}_{20}$ blends in toluene are shown in Figure 7a. In order to fix the concentration of the $\mathrm{P}_{20}$ in the solution, the different amount of PF powder is added into the $\mathrm{P}_{20} /$ toluene solution with the concentration of $10^{-4} \mathrm{~g} / \mathrm{g}$. And the concentrations of the PF in the solutions are 0 , $8 \times 10^{-6}, 1.3 \times 10^{-5}, 2.5 \times 10^{-5}$ and $5.0 \times 10^{-5} \mathrm{~g} / \mathrm{g}$, which are denoted as the $\mathrm{P}_{20} \mathrm{PF} 0, \mathrm{P}_{20} \mathrm{PF} 8, \mathrm{P}_{20} \mathrm{PF} 13$, $\mathrm{P}_{20} \mathrm{PF} 25$ and $\mathrm{P}_{20} \mathrm{PF} 50$, respectively. The emission spectra excited as $370 \mathrm{~nm}$ are normalized at $420 \mathrm{~nm}$. It can be found that the relative strength of g-band is decreased with increasing the content of the PF in Figure 7a. However, the strengths of g-band are identical when exciting $450 \mathrm{~nm}$ as shown in Figure $7 \mathrm{~b}$, that is, the strength of g-band is actually independent on the PF and depends on the fluorenone content when exciting at $450 \mathrm{~nm}$. The above results demonstrate that 

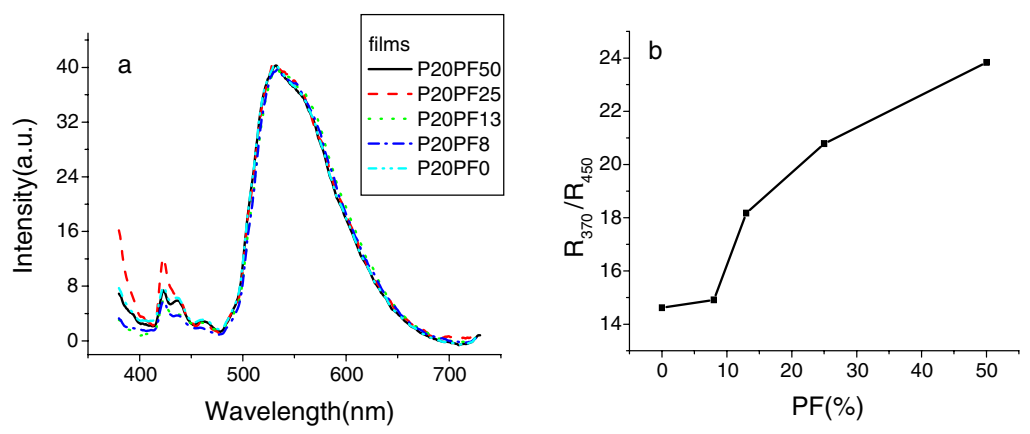

Figure 8. The emission spectra (a) and the intensity ratio of g-band strength excited at $370 \mathrm{~nm}$ to that excited at $450 \mathrm{~nm}(\mathrm{~b})$ of $\mathrm{P}_{20} / \mathrm{PF}$ blend films.

no interaction of fluorenone units occurs, which is because fluorene units closely pack the fluorenone unit, prevent approach of fluorenones. These phenomena are also different from those common to excimer emission.

The spectra of the $\mathrm{P}_{20} / \mathrm{PF}$ blending films are shown in Figure 8a. In the film, the spectra show very strong g-bands and very weak blue emissions, that is, the blue emission is suppressed and g-band is enhanced in the aggregated state when comparing with the emission properties in the corresponding solutions. This may be due to the decrease of blue-emission efficiency and the enhancement of the inter-chain energy transfer from PF segments to fluorenone units in the film. It can be also found that the strength of g-band excited at $370 \mathrm{~nm}\left(\mathrm{R}_{370}\right)$ is much higher than that excited at $450 \mathrm{~nm}\left(\mathrm{R}_{450}\right)$. The ratio of $R_{370} / R_{450}$ is above 14 when there is no dissociative PF in the system and is increased with increasing the PF content in the $\mathrm{P}_{20} / \mathrm{PF}$ blend films, which is possibly due to more energy transferring from $\mathrm{PF}$ chains to fluorenone units (Figure 8b). This is different from the experimental phenomenon that demonstrated the origin of g-band of the fluorenone excimer. ${ }^{17}$

\section{CONCLUSIONS}

The origin of g-band in the PF is studied by using $\mathrm{P}_{20}$ as a model polymer. The experiments rule out the fluorenone-based excimer origin and demonstrate the mono-chain fluorenone origin as the origin of gband. The aggregation of the conjugated polymer suppresses the blue emission and enhances g-band emission. This conclusions will provide a clear direction for future material research to minimize the formation of the fluorenone defect.

Acknowledgment. The financial support by $\mathrm{Na}-$ tional Natural Science Foundation of China (Grant No. 50473057, 20374055, 50521302) and Chinese Academy of Sciences (Grant No. KJCX2-SW-H07) is greatly appreciated.

\section{REFERENCES}

1. D. D. C. Bradley, M. Grell, A. Grice, R. Tajbakhsh, D. F. O'Brien, and A. Bleyer, Opt. Mater., 9, 1 (1998).

2. Y. Morisaki, H. Chen, and Y. Chujo, Polym. J., 35, 446 (2003).

3. H. Zhang, H. Chen, Y. Li, Q. Jiang, and M. Xie, Polym. Bull., 57, 121 (2006).

4. X. B. Ding, J. G. Zheng, Y. D. Jin, B. X. Peng, P. L. Heremans, G. Borghs, and H. J. Geise, Synth. Met., 142, 267 (2004).

5. B. Q. He, J. Li, Z. S. Bo, and Y. Huang, Macromolecules, 38, 6762 (2005).

6. J. F. de Deus, M. L. Andrade, T. D. Z. Atvars, and L. Akcelrud, Chem. Phys., 297, 177 (2004).

7. S. F. Lim, R. H. Friend, I. D. Rees, J. Li, Y. G. Ma, K. Robinson, A. B. Holmes, E. Hennebicq, D. Beljonne, and F. Cacialli, Adv. Funct. Mater., 15, 981 (2005).

8. L. Romaner, A. Pogantsch, P. S. de Freitas, U. Scherf, M. Gaal, E. Zojer, and E. J. W. List, Adv. Funct. Mater., 13, 597 (2003).

9. X. H. Yang, D. Neher, and C. Spitz, J. Chem. Phys., 119, 6832 (2003).

10. W. Zhao, T. Cao, and J. M. White, Adv. Funct. Mater., 14, 783 (2004).

11. X. W. Chen, H. E. Tseng, J. L. Liao, and S. A. Chen, J. Phys. Chem. B, 109, 17496 (2005).

12. J. I. Lee, G. Klaerner, and R. D. Miller, Synth. Met., 101, 126 (1999).

13. I. Prieto, J. Teetsov, M. A. Fox, D. A. V. Bout, and A. J. Bard, J. Phys. Chem. A, 105, 520 (2001).

14. V. N. Bliznyuk, S. A. Carter, J. C. Scott, G. Klarner, R. D. Miller, and D. C. Miller, Macromolecules, 32, 361 (1999).

15. E. J. W. List, R. Guentner, P. S. de Freitas, and U. Scherf, Adv. Mater., 14, 374 (2002).

16. U. Scherf and E. J. W. List, Adv. Mater., 14, 477 (2002).

17. M. Sims, D. D. C. Bradley, M. Ariu, M. Koeberg, A. Asimakis, M. Grell, and D. G. Lidzey, Adv. Funct. Mater., 14, 765 (2004).

18. F. M. Winnik, Chem. Rev., 93, 587 (1993).

19. E. Zojer, A. Pogantsch, E. Hennebicq, D. Beljonne, J. L. Bredas, P. S. de Freitas, U. Scherf, and E. J. W. List, J. Chem. Phys., 117, 6794 (2002).

20. X. Gong, D. Moses, A. J. Heeger, and S. Xiao, J. Phys. 
Chem. B, 108, 8601 (2004).

21. X. O. Gong, P. K. Iyer, D. Moses, G. C. Bazan, A. J. Heeger, and S. S. Xiao, Adv. Funct. Mater., 13, 325 (2003).

22. G. Klarner, J. I. Lee, M. H. Davey, and R. D. Miller, $A d v$. Mater., 11, 115 (1999).

23. M. R. Craig, M. M. de Kok, J. W. Hofstraat, A. P. H. J. Schenning, and E. W. Meijer, J. Mater. Chem., 13, 2861 (2003).

24. X. H. Yang, F. Jaiser, D. Neher, P. V. Lawson, J. L. Bredas, E. Zojer, R. Guntner, P. S. de Freitas, M. Forster, and U. Scherf, Adv. Funct. Mater., 14, 1097 (2004).

25. G. Klarner, M. H. Davey, W. D. Chen, J. C. Scott, and R. D. Miller, Adv. Mater., 10, 993 (1998).

26. G. Klarner, J. I. Lee, V. Y. Lee, E. Chan, J. P. Chen, A. Nelson, D. Markiewicz, R. Siemens, J. C. Scott, and R. D.
Miller, Chem. Mater., 11, 1800 (1999).

27. J. Li and Z. S. Bo, Macromolecules, 37, 2013 (2004).

28. C. Gadermaier, L. Romaner, T. Piok, E. J. W. List, B. Souharce, U. Scherf, G. Cerullo, and G. Lanzani, Phys. Rev. B, 72, 045208 (2005).

29. S. Gamerith, M. Gaal, L. Romaner, H. G. Nothofer, R. Guntner, P. S. de Freitas, U. Scherf, and E. J. W. List, Synth. Met., 139, 855 (2003).

30. E. J. W. List, M. Gaal, R. Guentner, P. S. de Freitas, and U. Scherf, Synth. Met., 139, 759 (2003).

31. J. Li, M. Li, and Z. S. Bo, Chem. Eur. J., 11, 6930 (2005).

32. N. Miyaura and A. Suzuki, Chem. Rev., 95, 2457 (1995).

33. G. Klaerner and R. D. Miller, Macromolecules, 31, 2007 (1998). 